\title{
Produção e caracterização de revestimentos de ligas metálicas Cu-Sn em banho eletrolítico contendo glicina: ensaios preliminares
}

\section{Production and characterization of metallic Cu-Sn alloy coatings in electrolytic bath containing glycine: preliminary experiments}

\author{
Priscila Santos da Silva ${ }^{1}$, Dalva Cristina Baptista do Lago ${ }^{1}$, \\ Lilian Ferreira de Senna ${ }^{1}$
}

\begin{abstract}
${ }^{1}$ Laboratório de Eletroquímica e Corrosão - LEC, Instituto de Química, Universidade do Estado do Rio de Janeiro UERJ, Rua São Francisco Xavier, 524, Pavilhão Haroldo Lisboa da Cunha, S. 427, Maracanã, CEP: 20550-013, Rio de Janeiro, Rio de Janeiro, Brasil.

e-mail: 1senna@uerj.br
\end{abstract}

\section{RESUMO}

Os problemas relacionados à corrosão são frequentes, podendo ocorrer nas mais variadas áreas, tais como, nas indústrias química, petroquímica, naval, de construção civil e automobilística, dentre outros setores produtivos. Portanto, métodos para prevenir a corrosão devem ser empregados para evitar a perda de materiais e o uso de revestimentos metálicos tem servido bastante a este propósito.

A produção de revestimentos metálicos permite modificar a superfície do substrato levando à formação de um material funcional que apresenta as propriedades e características desejadas, no caso, resistência à corrosão. Contudo, esses revestimentos são geralmente produzidos usando banhos tóxicos a base de cianeto, o que eleva o custo do processo devido ao tratamento posterior dos rejeitos gerados.

O presente trabalho propõe um estudo inicial para a produção de revestimentos de ligas de $\mathrm{Cu}-\mathrm{Sn}$ com propriedades anticorrosivas, a partir de banho eletrolítico menos agressivo, apresentando diferentes concentrações iônicas de cobre e estanho. Os revestimentos foram eletrodepositados em substrato de aço-carbono, utilizando eletrólitos ácidos contendo $\mathrm{CuCl}_{2}, \mathrm{SnCl}_{2}$ e glicina. Estes revestimentos foram posteriormente caracterizados através das técnicas de microscopia eletrônica de varredura (MEV), espectroscopia de raios $\mathrm{X}$ por energia dispersiva (EDS), espectroscopia de impedância eletroquímica (EIE) e polarização potenciodinâmica. Os resultados de EIE mostraram que os filmes produzidos com maiores teores de cobre apresentaram um aumento nos valores da resistência de transferência de carga $\left(\mathrm{R}_{\mathrm{tc}}\right)$. Contudo, os ensaios de polarização mostraram que estes filmes não atuaram como revestimentos protetores. As análises morfológicas evidenciaram a formação de revestimentos porosos, o que pode explicar seu pobre comportamento eletroquímico.

Palavras-chave: Corrosão, glicina, liga $\mathrm{Cu}-\mathrm{Sn}$, revestimento

\section{ABSTRACT}

The problems related to corrosion are frequent and may occur in many areas, such as the chemical, petrochemical, naval, civil construction and automobile industries, among other productive sectors. Therefore, corrosion prevention methods should be employed to avoid loss of materials and the use of metallic coatings has served well for this purpose.

The production of metallic coatings allows a modification on the substrate surface leading to the formation of a functional material that presents the desired properties and characteristics, in this case, corrosion resistance. However, these coatings are generally produced using toxic cyanide-based baths, which increases the cost of the process due to further treatment of the generated wastes.

The present work proposes an initial study aiming at producing of $\mathrm{Cu}-\mathrm{Sn}$ alloy coatings, with anticorrosive properties, originated from a less aggressive electrolytic bath, presenting different copper and tin ionic con- 
centrations. The coatings were electrodeposited on carbon steel substrate using an acidic electrolyte containing $\mathrm{CuCl}_{2}, \mathrm{SnCl}_{2}$ and glycine. These coatings were further characterized by scanning electron microscopy (SEM), X-ray spectroscopy energy dispersive (EDS), electrochemical impedance spectroscopy (EIS) and potentiodynamic polarization.

The results of EIS showed that the films produced with higher copper contents presented an increase in the values of the charge transfer resistance $\left(\mathrm{R}_{\mathrm{ct}}\right)$. However, the polarization experiments showed that these films did not act as protective coatings. The morphological analysis evidenced the formation of porous coatings, which may explain their poor electrochemical behavior.

Keywords: Corrosion, glycine, $\mathrm{Cu}-\mathrm{Sn}$ alloy, coating.

\section{INTRODUÇÃO}

A eletrodeposição é um dos métodos mais utilizados para a produção de filmes de metais e ligas metálicas em muitos processos tecnológicos e possui grande interesse econômico, pois permite que materiais menos nobres sejam empregados industrialmente, com excelentes resultados [1]. Os materiais obtidos por este processo devem possuir propriedades de resistência à corrosão, resistência mecânica, brilho, entre outras [2].

Entre os metais mais frequentemente utilizados para várias aplicações técnicas, o cobre pode ser citado devido à sua excelente condutividade elétrica e térmica, boa ductilidade e resistência à corrosão e à oxidação. No entanto, a baixa resistência mecânica do cobre, principalmente em altas temperaturas, e a indesejável resistência ao desgaste limitam a sua aplicação[3].

Ligas de Cu-Sn possuem ampla aplicação na indústria microeletrônica, pois apresentam características e propriedades como baixa tensão superficial, soldabilidade e ductilidade, além de apresentarem também uma maior resistência à corrosão, geralmente devido ao aumento do teor de Sn na liga[4]. Assim, a produção destas ligas como revestimentos é interessante do ponto de vista industrial, pois conferem melhores propriedades funcionais ao metal de base.

Atualmente, um item bastante importante relacionado aos métodos utilizados para a produção dos materiais é a questão ambiental, sendo necessário sempre levar esse aspecto em consideração. Revestimentos de ligas de cobre são geralmente produzidos por eletrodeposição, sendo o complexante mais utilizado para essa finalidade o cianeto. Porém, este possui elevada toxicidade e necessidade de um controle rigoroso das soluções após o uso. A utilização prolongada de banhos de cianeto também leva a um decréscimo na qualidade do revestimento produzido [1]. Assim, alternativas de banhos eletrolíticos para revestimentos de ligas de cobre que sejam eficientes e ao mesmo tempo ambientalmente favoráveis, vêm sendo estudadas [1, 5-7], tais como aqueles à base de citrato, gluconato, tartarato e glicinato. Todas estas substâncias são agentes complexantes não-tóxicos, de fácil obtenção e degradação $[6,8,9]$. Trabalhos anteriores do nosso grupo de pesquisa já mostraram que é possível a obtenção de revestimentos de ligas de cobre utilizando banhos não agressivos ao ambiente, apresentando brilho e boa aderência [5,7,10]. Para a eletrodeposição de ligas $\mathrm{Cu}-\mathrm{Sn}$, contudo, existem poucos trabalhos utilizando complexantes não agressivos [11-13]. Em alguns casos, estas substâncias têm sido estudadas apenas como aditivo ao banho e não como agente complexante [14-15].

Dessa forma faz-se necessário avaliar a produção de revestimentos metálicos de liga $\mathrm{Cu}$-Sn utilizando banhos ambientalmente não agressivos. Entre estes, a glicina pode ser citada por não ser tóxica ao ambiente e possuir baixo custo, além de produzir revestimentos de outras ligas de cobre com alta aderência [7]. Sendo assim, esse trabalho propôs um estudo inicial para a produção de revestimentos de ligas metálicas de $\mathrm{Cu}-\mathrm{Sn}$, utilizando eletrólitos em meio ácido, contendo $\mathrm{CuCl}_{2}, \mathrm{SnCl}_{2}$ e glicina.

\section{MATERIAIS E MÉTODOS}

\subsection{Corpos de prova}

Foram utilizados discos metálicos de aço-carbono AISI 1020, cuja composição química em \% massa está descrita na Tabela 1 [16]. Os discos apresentavam área média de aproximadamente $4.9 \mathrm{~cm}^{2}$.

Tabela 1: Composição química do aço carbono AISI 1020

\begin{tabular}{l|l|l|l|l|l|l|l|ll}
\hline ELEMENTO & $\mathbf{C}$ & $\mathbf{M n}$ & $\mathbf{P}$ & $\mathbf{S}_{\text {máx }}$ & $\mathbf{S i}$ & $\mathbf{C u}$ & $\mathbf{C r}$ & $\mathbf{N i}$ \\
\hline MASSA (\%) & 0,16 & 0,63 & 0,012 & 0,031 & 0,012 & 0,01 & 0,03 & 0,01 \\
\hline
\end{tabular}


Os discos foram lixados com lixas d'água de 100 mesh a 600 mesh de granulometria, polidos com alumina grau 2, lavados com água destilada e álcool etílico, e secos com jato de ar quente. Antes dos ensaios de eletrodeposição, os discos foram desengordurados em solução aquecida de lauril sulfato de sódio 0.5 g. $\mathrm{L}^{-1}$ e hidróxido de sódio 40 g. $\mathrm{L}^{-1}$.

\subsection{Preparo dos banhos eletrolíticos}

Foram preparadas duas soluções para os banhos eletrolíticos contendo diferentes concentrações de íons de $\mathrm{Cu}^{2+}$ e $\mathrm{Sn}^{2+}$, conforme descrito na Tabela 2. Essas concentrações foram escolhidas com base em resultados anteriores de nosso grupo de pesquisa [17].

Tabela 2: Composição das soluções utilizadas como banhos eletrolíticos

\begin{tabular}{|c|c|c|c|c|c|}
\hline SOLUÇÃO & $\begin{array}{c}\mathrm{CuCl}_{2} \cdot 2 \mathrm{H}_{2} \mathrm{O} \\
\left(\mathrm{mol} \cdot \mathrm{L}^{-1}\right)\end{array}$ & $\begin{array}{c}\mathrm{SnCl}_{2} \cdot 2 \mathrm{H}_{2} \mathrm{O} \\
\left(\mathrm{mol}^{-\mathrm{L}^{-1}}\right)\end{array}$ & $\begin{array}{l}\text { GLICINA } \\
\left(\mathrm{mol}^{-1} \mathrm{~L}^{-1}\right)\end{array}$ & $\begin{array}{c}\text { BENZOTRIAZOL } \\
\left(\mathrm{mol}^{\left.-\mathrm{L}^{-1}\right)}\right.\end{array}$ & $\mathrm{pH}$ \\
\hline 1 & 0,02 & 0,20 & 0,50 & 0,01 & 0,37 \\
\hline 2 & 0,20 & 0,02 & 0,50 & 0,01 & 0,65 \\
\hline
\end{tabular}

Como a solubilidade do composto $\mathrm{SnCl}_{2}$ no meio contendo glicina foi baixa, fez-se necessário empregar um meio muito ácido $(\mathrm{pH}<1)$ para que o sal de estanho pudesse ser solubilizado no banho proposto. Desse modo o benzotriazol, conhecido como um inibidor de corrosão efetivo [18-20], foi utilizado para tentar minimizar o ataque do meio ácido ao substrato de aço, evitando, assim, sua corrosão durante os ensaios de produção dos revestimentos.

\subsection{Ensaios Eletroquímicos}

\subsubsection{Curvas de polarização potenciodinâmica}

Foi realizado o levantamento das curvas de polarização potenciodinâmica catódica nos eletrólitos estabelecidos, com velocidade de agitação de $300 \mathrm{rpm}$, em um intervalo de potencial entre o potencial de circuito aberto e $-2,00 \mathrm{~V}$ (ECS) e velocidade de varredura de $1 \mathrm{mV} \mathrm{s}^{-1}$. Os ensaios foram realizados utilizando o potenciostato Autolab modelo PGSTAT302N, com uma célula eletroquímica contendo três eletrodos: o eletrodo de trabalho (aço-carbono), o eletrodo de referência de calomelano saturado (ECS), e um contraeletrodo de platina.

\subsubsection{Ensaios de eletrodeposição (produção do revestimento)}

A partir dos resultados de polarização potenciodinâmica, foram selecionadas dois valores de densidades de corrente para cada solução $\left(\mathrm{j}=10 \mathrm{~A} \cdot \mathrm{m}^{-2} \mathrm{e} \mathrm{j}=100 \mathrm{~A} \cdot \mathrm{m}^{-2}\right)$ visando a realização dos ensaios de eletrodeposição. Assim, os revestimentos foram produzidos em duplicatas para cada densidade de corrente escolhida, nas duas soluções (Solução 1 e Solução 2) e com velocidade de agitação de 300 rpm.

\subsubsection{Caracterização dos revestimentos metálicos}

\section{A) Caracterização morfológica}

A análise morfológica dos revestimentos produzidos foi realizada em um microscópio eletrônico de varredura JEOL, modelo JSM G510 LV, em alto vácuo, detector SEI e tensão de $20 \mathrm{kV}$. Espectroscopia de raios X por energia dispersiva (EDS) também foi utilizada para analisar quantitativamente as amostras.

\section{B) Caracterização Química}

Os teores dos elementos formadores da liga foram obtidos, após dissolução dos revestimentos em ácido nítrico $20 \% \mathrm{v} / \mathrm{v}$, utilizando espectrometria de emissão óptica por plasma indutivamente acoplado (ICP-OES THERMO SCIENTIFIC, modelo iCAP 6000 Series). 


\section{C) Caracterização eletroquímica}

Para verificar a resistência à corrosão dos revestimentos, foram realizados ensaios de espectroscopia de impedância eletroquímica (EIE) e polarização potenciodinâmica. Nos ensaios de EIE, realizados no potencial de circuito aberto, foi utilizada uma faixa de frequência de $10^{5} \mathrm{~Hz} \mathrm{a} 10^{-3} \mathrm{~Hz}$, com uma amplitude de $10 \mathrm{mV}$. Para os ensaios de polarização potenciodinâmica, a faixa de potencial aplicada foi de $-0,5 \mathrm{~V}$ a $+0,5 \mathrm{~V}$, em torno do potencial de circuito aberto, com velocidade de varredura de $1 \mathrm{mV} . \mathrm{s}^{-1}$. Todos os ensaios eletroquímicos foram feitos após estabilização do sistema em seu potencial de circuito aberto por aproximadamente $1 \mathrm{~h}$. O eletrólito utilizado nos ensaios eletroquímicos foi uma solução de $\mathrm{NaCl} 0,5 \mathrm{~mol} . \mathrm{L}^{-1}$. Os ensaios foram realizados utilizando o potenciostato Autolab modelo PGSTAT302N, com uma célula eletroquímica contendo três eletrodos: o eletrodo de trabalho (aço-carbono revestido com a liga $\mathrm{Cu}-\mathrm{Sn}$ ), o eletrodo de referência de calomelano saturado (ECS) e um contraeletrodo de platina. Os dados obtidos a partir dos ensaios de EIE foram simulados através de circuitos elétricos equivalentes, utilizando o software NOVA 1.10 Metrohm Autolab.

\section{RESULTADOS}

\subsection{Curvas de polarização}

A Figura 1 exibe as curvas de polarização obtidas para o eletrodo de aço-carbono nos dois banhos eletrolíticos contendo diferentes concentrações de íons $\mathrm{Cu}^{2+}$ e $\mathrm{Sn}^{2+}$. A polarização foi realizada com o objetivo de selecionar os valores de densidade de corrente $(\mathrm{j})$ para os ensaios de eletrodeposição e verificar o efeito das concentrações dos íons metálicos no processo de eletrodeposição.

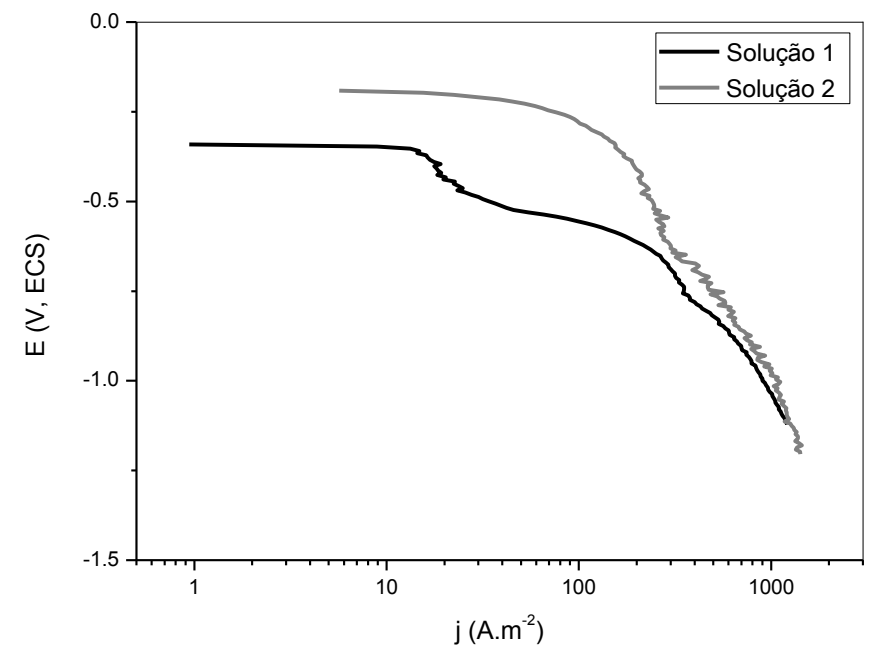

Figura 1: Curvas de polarização para o aço-carbono nos diferentes eletrólitos.

Pela diferença entre os potenciais de redução dos íons $\mathrm{Cu}^{2+}\left(\mathrm{E}^{\mathrm{o}}=0,34 \mathrm{~V}_{\mathrm{EPH}}\right.$ e $\mathrm{Sn}^{2+}\left(\mathrm{E}^{\mathrm{o}}=-0,14 \mathrm{~V}_{\mathrm{EPH}}\right)$, espera-se que a redução dos íons $\mathrm{Cu}^{2+}$ ocorram em menores valores de potencial. Sendo o modo de deposição da liga $\mathrm{Cu}-\mathrm{Sn}$ considerado regular [21], a redução do íon do metal mais nobre (no caso, $\mathrm{Cu}^{2+}$ ) ocorre preferencialmente e em potenciais menos negativos. Adicionalmente, com base na lei de Nernst, o aumento da concentração da espécie em solução desloca seu potencial de redução para valores menos negativos. Assim, a partir das curvas de polarização (Figura 1) é possível observar que a condição em que o eletrólito continha maior concentração de $\mathrm{Cu}^{2+}$ (Solução 2) apresentou uma despolarização do substrato, significando que a redução dos íons do metal mais nobre foi facilitada, o que pode dificultar, consequentemente, a deposição dos íons $\mathrm{Sn}^{+2}$. Por outro lado, na condição contendo maior quantidade de $\mathrm{Sn}^{2+}$ (Solução 1), a curva de polarização se inicia em potenciais mais negativos, dificultando a redução dos íons de cobre e favorecendo, provavelmente, a deposição do estanho. Contudo, é importante ressaltar que em maiores densidades de corrente catódica (potenciais muito negativos), as duas curvas estão muito próximas entre si. Como o meio usado é muito ácido em função das limitações apresentadas anteriormente, a reação de redução de íons $\mathrm{H}^{+}$(HER) deve prevalecer à redução dos íons $\mathrm{Sn}^{2+}$ nesta região. Com base na Figura 1, os revestimentos metálicos de $\mathrm{Cu}-\mathrm{Sn}$ foram produzidos nas densidades de corrente (j) de $10 \mathrm{~A} \cdot \mathrm{m}^{-2}$ e $100 \mathrm{~A} \cdot \mathrm{m}^{-2} \mathrm{em}$ ambas as soluções. 


\subsection{Caracterização dos Revestimentos}

\subsubsection{Caracterização morfológica e semiquantitativa (MEV e EDS)}

As micrografias obtidas para as superfícies dos revestimentos de ligas $\mathrm{Cu}-\mathrm{Sn}$, produzidos na Solução 1 da Tabela 2, a partir das densidades de corrente selecionadas, são apresentadas na Figura 2. A Figura 3 mostra os espectros de EDS referentes aos revestimentos apresentados.
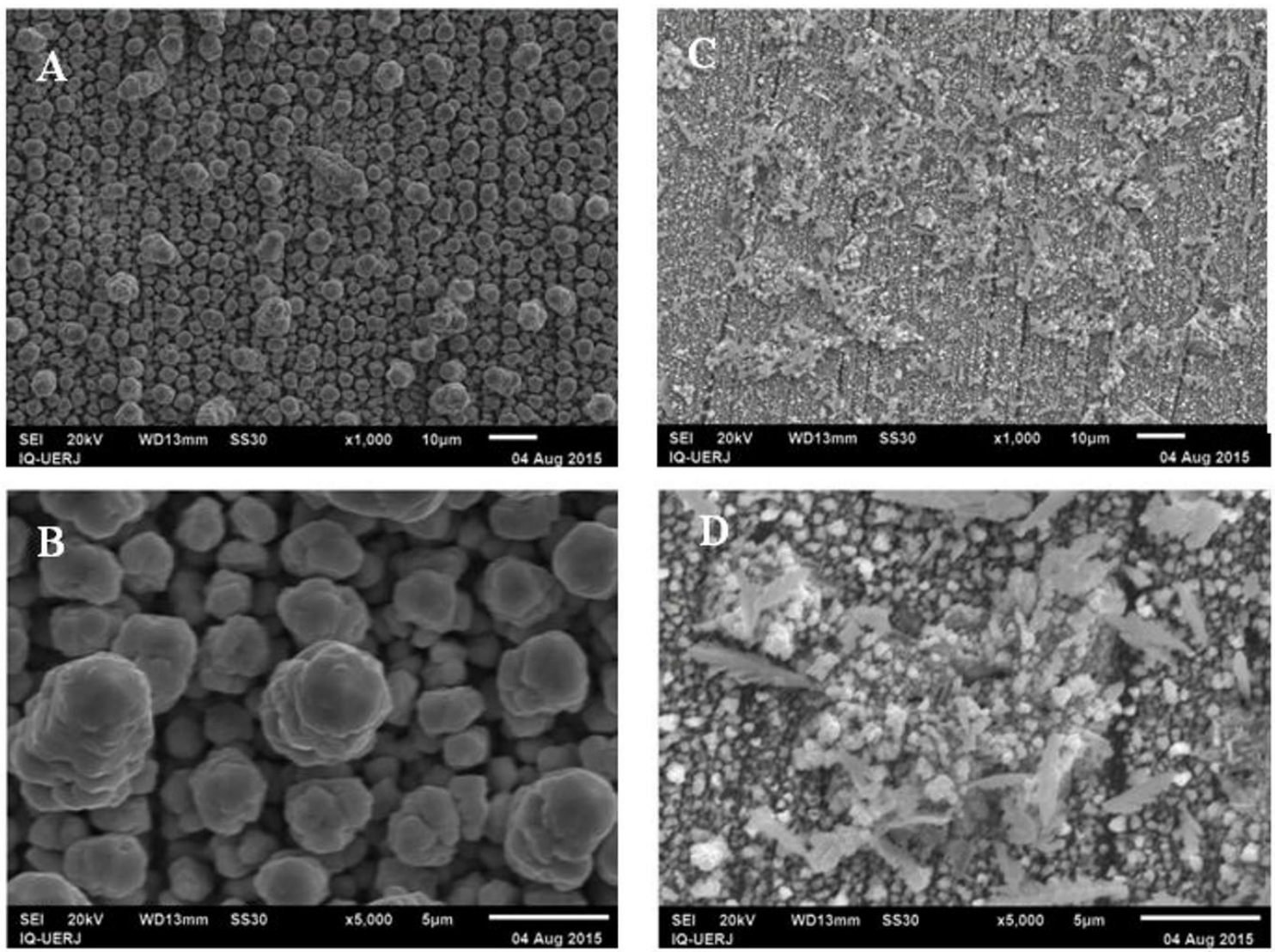

Figura 2: Micrografias dos revestimentos $\mathrm{Cu}-\mathrm{Sn}$ produzidos a partir da Solução 1, utilizando as densidades de corrente selecionadas: $\mathrm{j}=10$ A.m $\mathrm{m}^{-2}$, com aumento de 1000X (A) e 5000X (B); $\mathrm{j}=100 \mathrm{~A} \cdot \mathrm{m}^{-2}$, com aumento de 1000X (C) e 5000X (D).

As Figuras 2A e 2B mostram a superfície do eletrodepósito obtido a partir do banho contendo maior concentração de íons $\mathrm{Sn}^{+2}$ (Solução 1) e densidade de corrente de $10 \mathrm{~A} \cdot \mathrm{m}^{-2}$. Este revestimento apresentou-se uniforme, com grãos bem distribuídos sobre a superfície. Morfologia de revestimentos de ligas $\mathrm{Cu}-\mathrm{Sn}$ em forma de grãos é bem reportada na literatura [22-24]. Quando a densidade de corrente foi variada para $100 \mathrm{~A}$. $\mathrm{m}^{-2}$ (Figuras 2C e 2D), o revestimento exibiu um aspecto diferente, com formação de grãos menores, além de uma morfologia dendrítica. Resultado semelhante foi encontrado por Silva Jr. [17] em seu estudo sobre a produção de revestimentos de ligas $\mathrm{Cu}-\mathrm{Sn}$ em meio de citrato, usando potenciais mais negativos, e por Correia, Façanha e Lima-Neto [25] em seu trabalho sobre o comportamento de revestimentos de ligas $\mathrm{Cu}-\mathrm{Sn}$ produzidos em meio de pirofosfato e $\mathrm{pH}$ ácido. Estes autores relacionaram a forma dendrítica do revestimento com um aumento da deposição do $\mathrm{Cu}$ na liga, o que consequentemente dificultou a deposição do Sn. Isso ocorreu mesmo quando a solução usada para eletrodeposição continha uma menor concentração de íons $\mathrm{Cu}^{2+}$. Essa morfologia dendrítica sugere também uma baixa aderência do revestimento à superfície [17]. As diferenças encontradas nos resultados de MEV indicam a influência do parâmetro densidade de corrente na produção do eletrodepósito.

$\mathrm{O}$ espectro de EDS ilustrado na Figura 3A mostra os elementos que compõem a camada de liga $\mathrm{Cu}-\mathrm{Sn}$ obtida a partir do banho eletrolítico contendo a maior concentração de íons $\operatorname{Sn}^{+2}$ (Solução 1) e aplicação de 
uma densidade de corrente de 10 A.m². Foram detectados picos de $\mathrm{Cu}$ e $\mathrm{Sn}$ em maior intensidade, sugerindo que estes elementos foram eletrodepositados satisfatoriamente, formando o revestimento, como o esperado. $\mathrm{O}$ pico de Fe está associado ao substrato de aço carbono. Já para a liga $\mathrm{Cu}-\mathrm{Sn}$ obtida no mesmo banho, porém com densidade de corrente de 100 A.m² (Figura 3B), a intensidade do pico do Sn diminuiu significativamente, indicando que a deposição deste elemento foi desfavorecida com o aumento da densidade de corrente, provavelmente em função da HER. Estes resultados estão de acordo com as diferenças encontradas na morfologia destes revestimentos (Figura 2), conforme também verificado por Correia, Façanha e Lima-Neto[25].
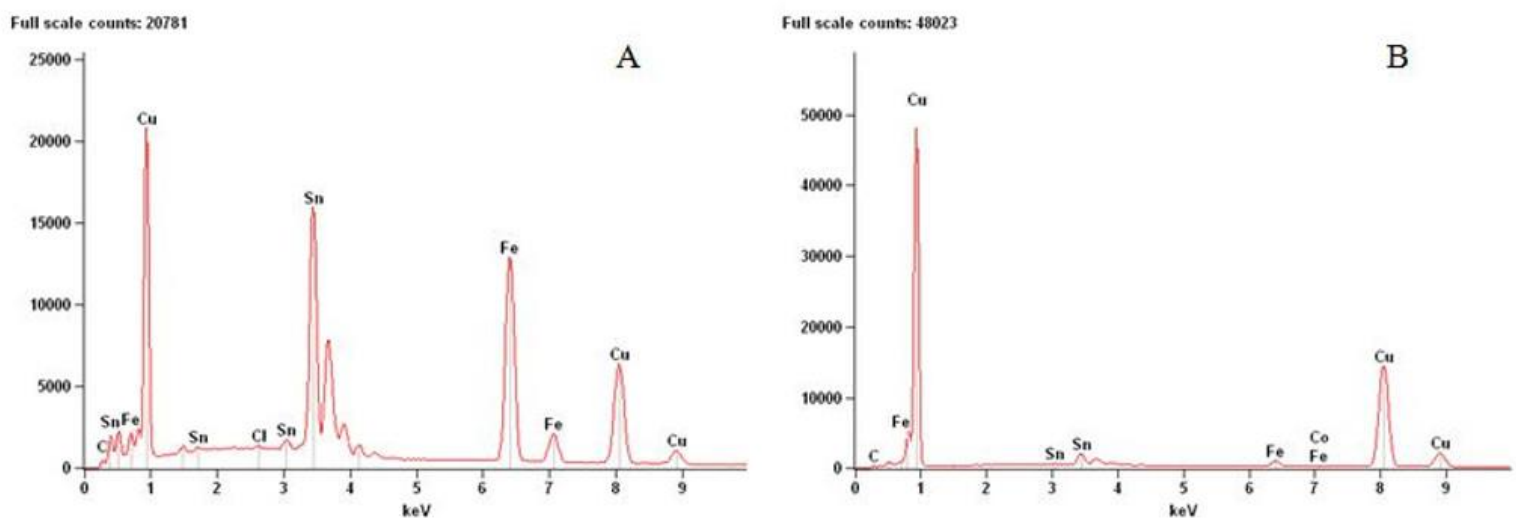

Figura 3: Espectros de EDS para os revestimentos Cu-Sn produzidos a partir da Solução 1 (A) j = 10 A.m - $^{-2}$ (B) $\mathrm{j}$ $=100 \mathrm{~A} \cdot \mathrm{m}^{-2}$.

As Figuras 4 e 5 apresentam, respectivamente, as micrografias obtidas para as superfícies dos revestimentos de ligas $\mathrm{Cu}-\mathrm{Sn}$, produzidos na Solução 2 da Tabela 2, a partir das densidades de corrente selecionadas, e os espectros de EDS referentes a estes revestimentos.
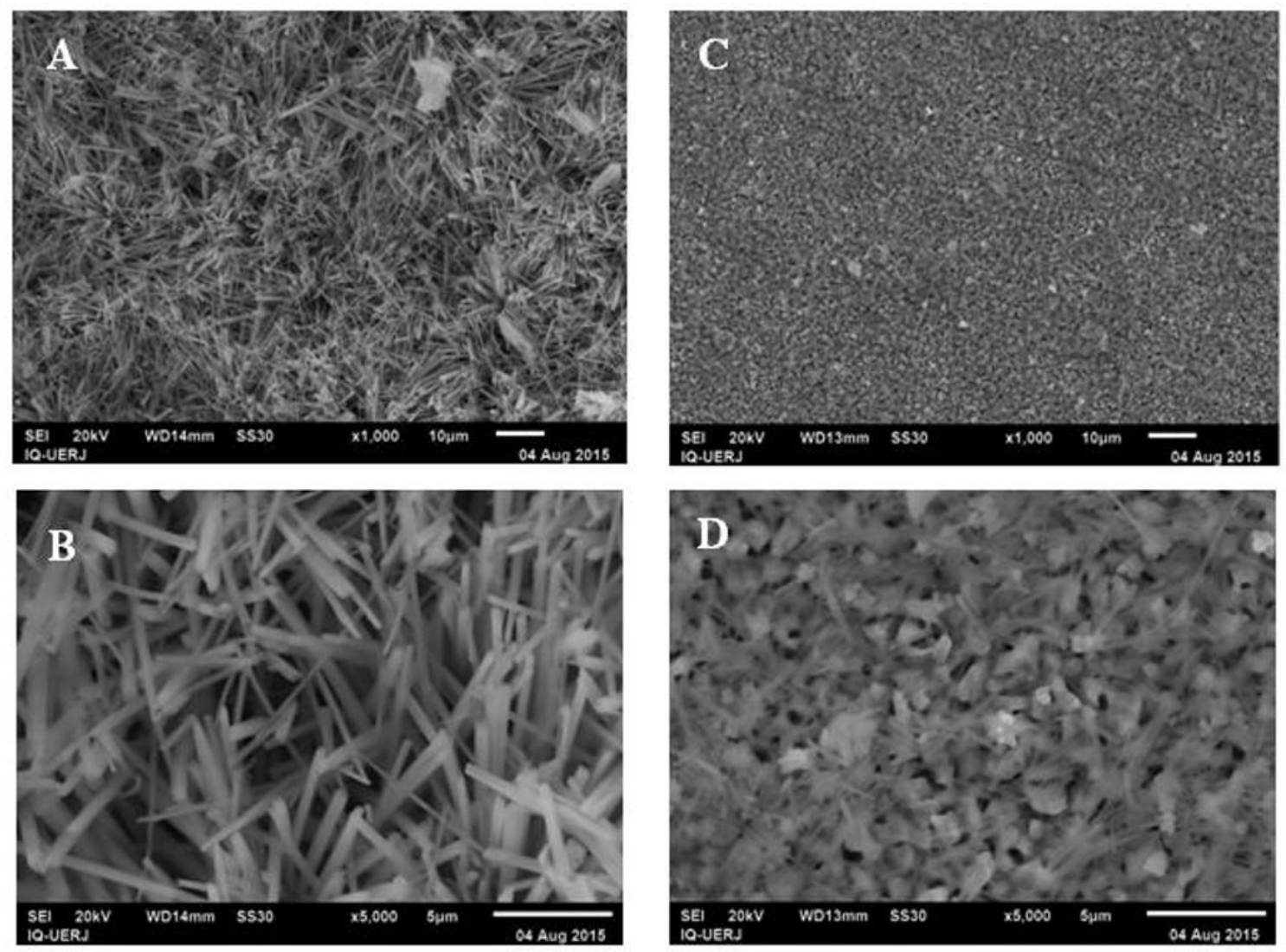
Figura 4: Micrografias dos revestimentos $\mathrm{Cu}-\mathrm{Sn}$ produzidos a partir da Solução 2, utilizando as densidades de corrente selecionadas: $\mathrm{j}=10$ A.m $\mathrm{m}^{-2}$, com aumento de 1000X (A) e 5000X (B); $\mathrm{j}=100 \mathrm{~A} \cdot \mathrm{m}^{-2}$, com aumento de $1000 X(C)$ e $5000 X(D)$.

Para a superfície do revestimento obtido no banho contendo maior concentração de íons $\mathrm{Cu}^{+2}$ (Solução 2), a morfologia encontrada foi bem diferente da anterior. No valor de densidade de corrente de $10 \mathrm{~A} \cdot \mathrm{m}^{-2}$ (Figuras 4A e 4B), o revestimento apresentou uma superfície também uniforme, mas aparentemente porosa, e com uma morfologia de agulhas. No revestimento produzido sob densidade de corrente de 100 A.m ${ }^{-2}$ (Figuras $4 \mathrm{C}$ e 4D), a superfície apresentou uma morfologia mista, variando entre a forma de grãos e agulhas.
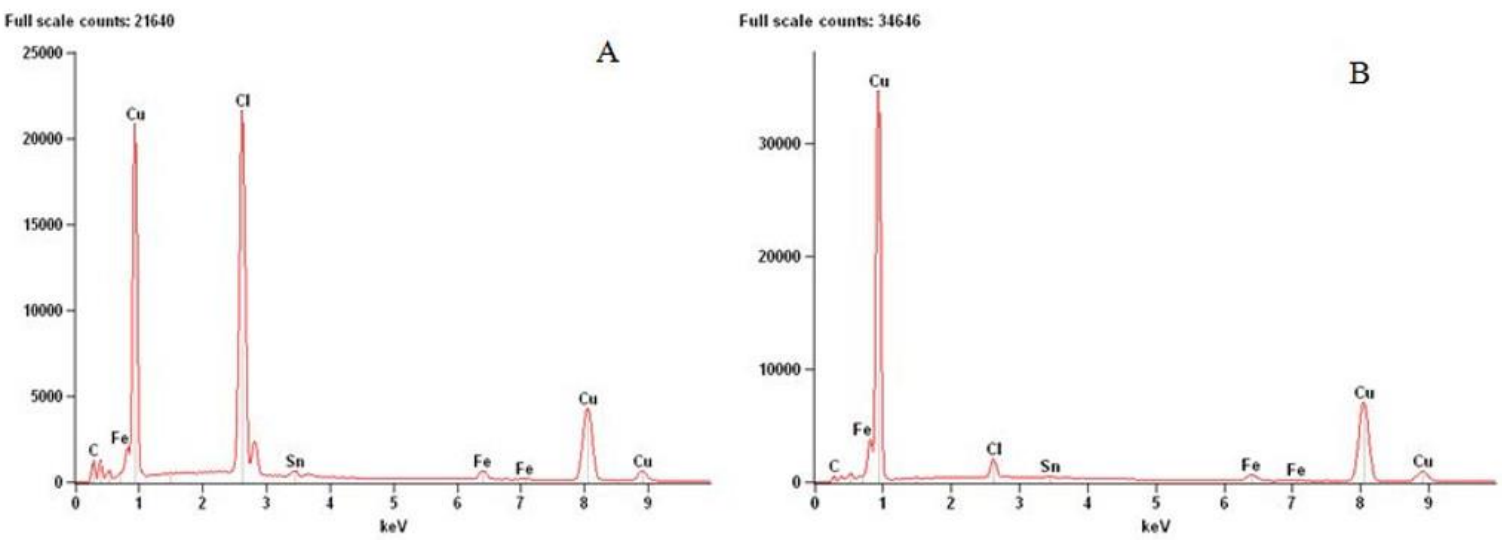

Figura 5: Espectros de EDS para os revestimentos $\mathrm{Cu}-\mathrm{Sn}$ produzidos a partir da Solução 2 (A) $\mathrm{j}=10 \mathrm{~A} \mathrm{~m}^{-2}$; (B) $\mathrm{j}$ $=100 \mathrm{~A} \mathrm{~m}^{-2}$.

Para o espectro de EDS do filme $\mathrm{Cu}-\mathrm{Sn}$ obtido no banho contendo maior concentração de íons $\mathrm{Cu}^{+2}$ (Solução 2) e j = 10 A.m ${ }^{-2}$ (Figura 5A), além dos picos de Cu e Sn também foi observado um pico de $\mathrm{Cl}$ em alta intensidade, devido à presença de meio ácido $(\mathrm{HCl})$ no banho, o qual foi utilizado para solubilizar o Sn. Correia, Façanha e Lima-Neto [25] também observaram pico de $\mathrm{Cl}$ no espectro de EDS utilizado para caracterizar ligas de $\mathrm{Cu}-\mathrm{Sn}$ obtidas em meio de pirofosfato e $\mathrm{HCl}$. Esses autores verificaram que, em meio ácido, após a dissolução do cobre eletrodepositado na solução, a superfície do eletrodo foi coberta com uma camada densa do complexo $\mathrm{CuCl}_{2}{ }^{-}$. Os resultados apresentados no presente trabalho sugerem que esse complexo pode ter sido formado no banho de eletrodeposição, possibilitando que os íons $\mathrm{Cu}^{2+}$ fossem reduzidos diretamente desse complexo [26], ou incorporados à superfície do substrato, na forma de cloretos. Isso poderia resultar no aspecto diferenciado da morfologia em agulhas observada na análise de MEV (Figuras 4A e 4B). Quando o valor de j foi aumentado para $100 \mathrm{~A} . \mathrm{m}^{-2}$, a intensidade desse pico de $\mathrm{Cl}$ diminuiu.

De maneira geral, os espectros obtidos sugerem que no processo de eletrodeposição com a Solução 2, há a formação de revestimentos de $\mathrm{Cu}$ com baixas concentrações de $\mathrm{Sn}$. Sendo essa uma análise semiquantitativa, essa suposição deverá ser confirmada pela caracterização química dos revestimentos.

\subsubsection{Caracterização Química}

A Tabela 3 mostra os teores de Cu e $\mathrm{Sn}$, em $\% \mathrm{~m} / \mathrm{m}$, obtidos a partir da técnica de ICP-OES para os revestimentos produzidos. A mesma tabela também apresenta os valores de espessura teórica (h) desses revestimentos, calculados pela Equação 1 [4]:

Tabela 3: Teores de $\mathrm{Cu}$ e $\mathrm{Sn}$ nos revestimentos de $\mathrm{Cu}-\mathrm{Sn}$, produzidos a partir das soluções da Tabela 2

\begin{tabular}{|c|c|c|c|}
\hline Amostras & $\begin{array}{c}\text { Teor de Cu } \\
(\% \mathrm{~m} / \mathrm{m})\end{array}$ & $\begin{array}{c}\text { Teor de Sn } \\
(\% \mathrm{~m} / \mathrm{m})\end{array}$ & $\begin{array}{c}\mathbf{h} \\
(\mu \mathbf{m})\end{array}$ \\
\hline $\begin{array}{c}\text { Solução 1 e } \\
\text { j = 10 A.m² } \\
\text { (Experimento 1) }\end{array}$ & 96,56 & 3,44 & 2,10 \\
\hline $\begin{array}{c}\text { SOLUÇÃO } 1 \text { e } \\
\text { j= 100 A.m } \\
\text { (Experimento 2) }\end{array}$ & 98,10 & 1,90 & 1,76 \\
\hline
\end{tabular}




\begin{tabular}{|c|c|c|c|}
\hline $\begin{array}{c}\text { SOLUÇÃ̃ } 2 \text { e } \\
\text { j = 10 A.m }{ }^{-2} \\
\text { (Experimento 3) }\end{array}$ & 98,85 & 1,15 & 3,44 \\
\hline $\begin{array}{c}\text { SOLUÇÃO 2 e } \\
\text { j = 100 A.m-2 } \\
\text { (Experimento 4) }\end{array}$ & 99,25 & 0,75 & 2,26 \\
\hline
\end{tabular}

$$
h=t\left(\frac{M_{c} i}{\rho_{c} z F A}\right)
$$

onde: $M_{c}$ e $\rho_{c}$ são, respectivamente, a massa molar $\left(\mathrm{g} \cdot \mathrm{mol}^{-1}\right)$ e a massa específica $\left(\mathrm{g} \cdot \mathrm{cm}^{-3}\right)$ do material depositado, considerando a composição química de cada revestimento; $t$ é o tempo de deposição (s), calculado com base na Lei de Faraday; $i$ é a corrente aplicada (A); $z$ é o número de elétrons envolvidos; $F$ é a constante de Faraday $\left(\mathrm{F}=96.485\right.$ A.s.mol $\left.{ }^{-1}\right)$ e A é área do eletrodo $\left(\mathrm{cm}^{2}\right)$.

Ao analisar estes resultados é possível observar que, para todas as camadas produzidas, o teor de $\mathrm{Cu}$ foi sempre muito superior ao do Sn, mesmo no eletrólito contendo maior concentração iônica deste metal. Em meio ácido, a glicina pode complexar com o cobre formando o complexo [CuGl] ${ }^{+}$[27] e com o estanho formando $[\mathrm{SnGl}]^{+}$ou $\left[\mathrm{SnHGl}^{2+}[28]\right.$. É possível sugerir que o baixo teor de estanho depositado no revestimento tenha ocorrido devido à formação de complexos estáveis de Sn-Glicina, o que pode ter desfavorecido a redução de íons $\mathrm{Sn}^{+2}$, facilitando a deposição de íons $\mathrm{Cu}^{+2}$. Porém, novos experimentos ainda são necessários para que seja possível uma conclusão mais definitiva sobre esse assunto. Adicionalmente, verifica-se que filmes da ordem de micrometros foram depositados. Embora fosse esperado [4], nota-se que não há uma relação direta entre a composição da liga e a espessura calculada dos revestimentos. O filme com maior espessura foi aquele obtido usando as condições do Experimento 3 (Solução 2; j = 10 A.m ${ }^{-2}$ ).

Entre todos os revestimentos produzidos, a Tabela 3 mostra que apenas aquele obtido a partir das condições do Experimento 1 apresentou composição mais próxima àquela da liga de bronze comercial (95\% $\mathrm{m} / \mathrm{m} \mathrm{Cu}-5 \% \mathrm{~m} / \mathrm{m} \mathrm{Sn}$ ). Esse resultado está de acordo com o que foi visualizado no espectro de EDS (Figura 3A) para esta condição, em que foi observado o maior pico de Sn. Porém, quando o valor da densidade de corrente foi aumentado, o teor de Sn diminuiu, provavelmente pelo favorecimento da redução dos íons $\mathrm{H}^{+}$, muito abundantes no meio. Pode-se notar também na Tabela 3 que, para as ligas obtidas no eletrólito contendo maior concentração de íons $\mathrm{Cu}^{2+}$, obteve-se maior teor de $\mathrm{Cu}$ e menor teor de $\mathrm{Sn}$, tal como o esperado, por tratar-se de uma deposição regular.

\subsubsection{Caracterização Eletroquímica}

\subsubsection{Espectroscopia de impedância eletroquímica (EIE)}

A técnica de EIE foi utilizada para avaliar a resistência à corrosão dos revestimentos de liga Cu-Sn em comparação com o substrato de aço-carbono nu. Os diagramas de Nyquist e Bode (módulo e fase) para os diferentes revestimentos obtidos e para o aço-carbono em meio de $\mathrm{NaCl} 0,5$ mol. $\mathrm{L}^{-1}$, são apresentados na Figura 6.

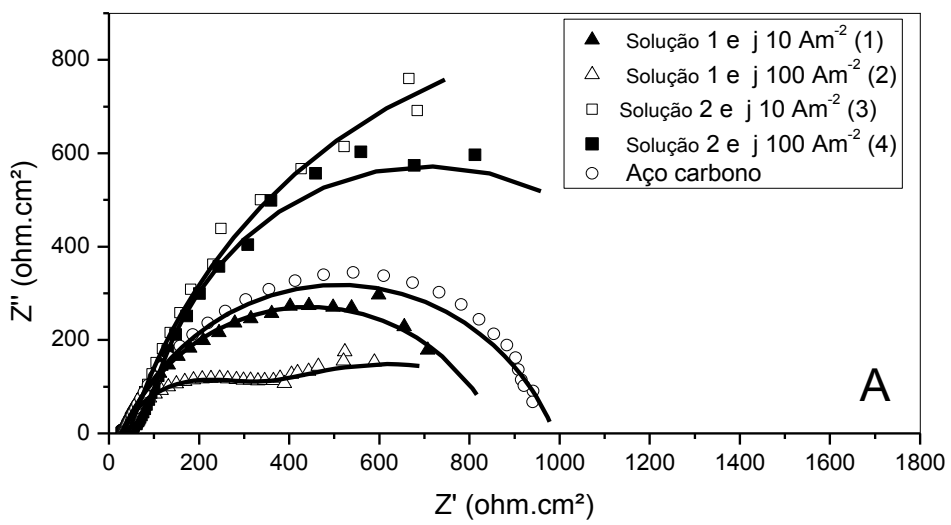



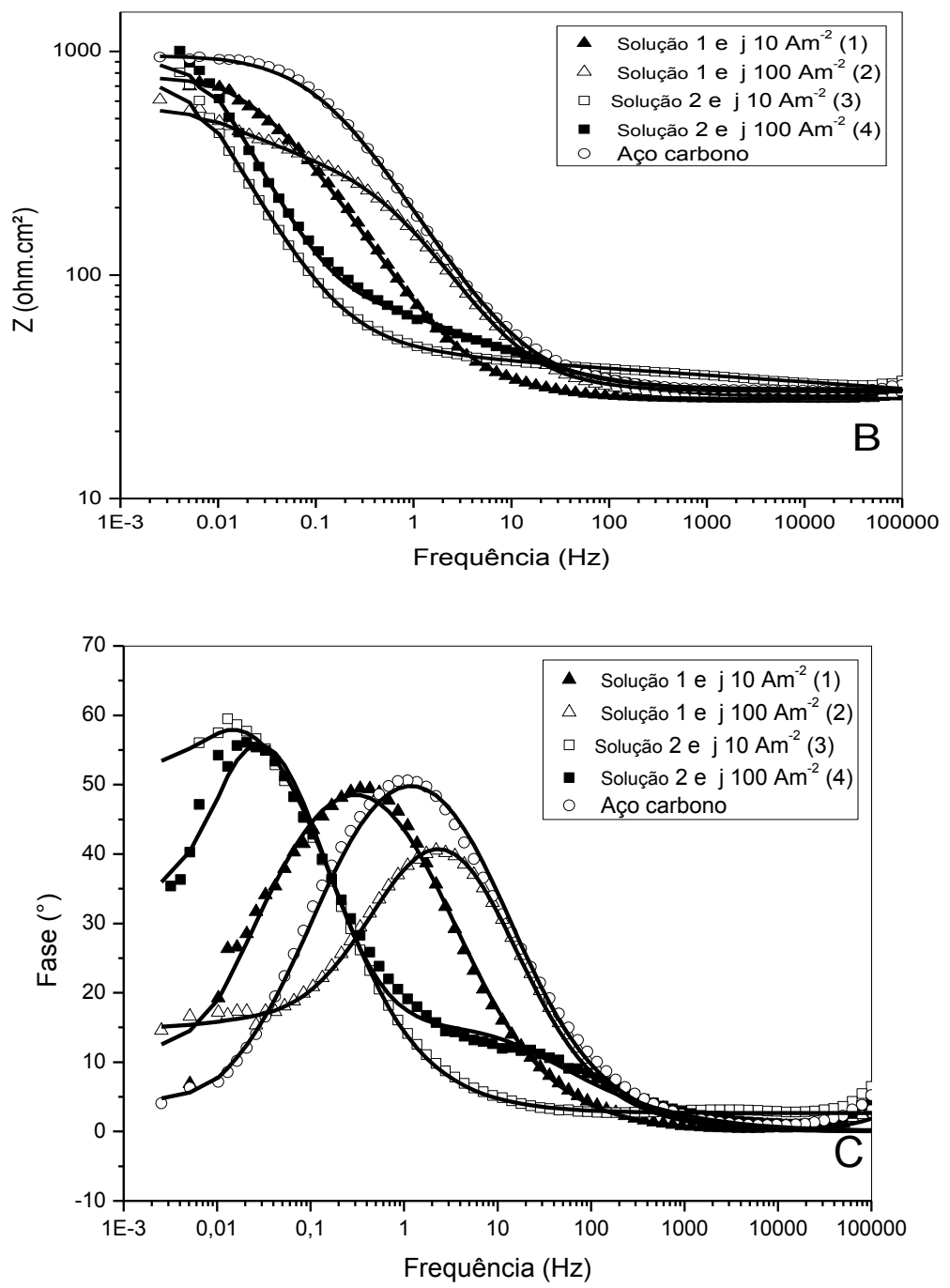

Figura 6: Diagramas de Nyquist (A), Bode (B) e fase (C) para os revestimentos Cu-Sn e para o aço carbono em meio de $\mathrm{NaCl} 0,5$ mol. $\mathrm{L}^{-1}$.

Considerando que os diâmetros dos arcos capacitivos no diagrama de Nyquist (Figura 6A) indicam maior resistência do revestimento à transferência de carga, observa-se que apenas dois dos revestimentos, produzidos a partir dos Experimentos 3 e 4 da Tabela 3, apresentaram arcos capacitivos maiores, em comparação com aqueles obtidos a partir do ensaio em branco (substrato de aço-carbono nu). Esses resultados sugerem que tais revestimentos seriam protetores, dificultando a corrosão do substrato. Já para os filmes obtidos nos eletrólitos com maior concentração de Sn (Experimentos 1 e 2) o tamanho dos arcos capacitivos mostrouse menor do que para o aço-carbono não recoberto, indicando que estes revestimentos não apresentaram uma resistência à corrosão satisfatória.

Analisando os diagramas de módulo (Figura 6B) é possível notar, contudo, que os valores de módulos de impedância em baixas frequencias, para todos os revestimentos preparados, são menores que do aço não revestido. Para ambos os revestimentos obtidos no banho eletrolítico contendo a maior concentração de $\mathrm{Cu}^{2+}$ (Experimentos 3 e 4), observa-se um ligeiro aumento no valor de módulo de Z, embora o comportamento capacitivo esteja deslocado para menores valores de frequência, em comparação ao ensaio em branco e também aos outros dois revestimentos (Experimentos 1 e 2). Adicionalmente, nenhum dos revestimentos mostra uma característica puramente protetora, pois todos os ângulos de fase (Figura 6C) são menores que $90^{\circ}$. Para a mesma comparação anteriormente realizada, os diagramas de fase dos revestimentos produzidos a partir das condições dos Experimentos 3 e 4 apresentam um deslocamento do valor máximo do ângulo de fase para 
menores valores de frequência, provavelmente relacionado a produtos de corrosão com características semicondutoras [29,30], formados no meio salino aerado durante o período de estabilização do potencial (1h). Além disso, o filme formado nas condições do Experimento 4 apresenta um ombro em frequências intermediárias (Figura 6C), indicando uma segunda constante de tempo, provavelmente relacionada ao revestimento metálico na superfície do aço. Assim, os resultados dos diagramas de módulo e fase sugerem que, apesar de apresentarem maiores tamanhos de arcos capacitivos no diagrama de Nyquist, os filmes de $\mathrm{Cu}$-Sn formados sobre a superfície do aço-carbono a partir da solução com maior concentração de $\mathrm{Cu}^{2+}$, não se caracterizaram como revestimentos protetores, como seria esperado para esse tipo de revestimento metálico [22]. Com base nas morfologias observadas na Figura 4, filmes porosos foram formados nessas condições, os quais podem não ter sido capazes de impedir o processo corrosivo do metal no eletrólito (solução de $\mathrm{NaCl} 0,5 \mathrm{~mol} \mathrm{~L}^{-1}$ ).

Para melhor interpretar os resultados obtidos a partir da técnica de impedância eletroquímica, os dados obtidos foram simulados utilizando modelos de circuitos elétricos equivalentes, onde os parâmetros resistência de transferência de carga $\left(\mathrm{R}_{\mathrm{tc}}\right)$ e capacitância da dupla camada elétrica $\left(\mathrm{C}_{\mathrm{DCE}}\right)$ são obtidos pela simulação do processo eletroquímico. A Figura 7A ilustra o circuito utilizado para simular os dados de EIE para o aço carbono, onde $\mathrm{R}_{\mathrm{e}}$ representa a resistência do eletrólito, $\mathrm{R}_{\mathrm{tc}}$ é a resistência à transferência de carga, e EFC representa a admitância do elemento de fase constante, associado com a capacitância da dupla camada elétrica. Já para os revestimentos $\mathrm{Cu}$-Sn, os dados de EIE foram simulados utilizando modelos de circuito equivalente diferentes, apresentados nas Figuras 7B e 7C, devido à presença de um filme (o revestimento) sobre o substrato de aço-carbono. Nesse caso, $\mathrm{R}_{\mathrm{f}} \mathrm{e} \mathrm{EFC}_{\mathrm{f}}$ se referem à resistência e à admitância do elemento de fase constante do filme, respectivamente.

O circuito da Figura 7B foi utilizado para ajustar os dados obtidos a partir dos Experimentos 1 e 2. Para esses casos, considera-se que a primeira constante de tempo descreve as características dielétricas de um revestimento com defeitos e/ou porosidades e a resistência do eletrólito que permeia através dos poros $\left(\mathrm{R}_{\mathrm{f}}\right.$ EFC). Em paralelo, tem-se outro circuito que representa o processo do eletrodo, descrito pela resistência de transferência de carga e pelas características capacitivas que se formam na interface entre o eletrólito e o metal no fundo dos poros $\left(\mathrm{R}_{\mathrm{tc}}-\mathrm{EFC}\right)$ [31]. Aqui, $\mathrm{R}_{\mathrm{e}}$ representa a resistência da solução. Por outro lado, um melhor ajuste foi verificado para os revestimentos produzidos a partir dos Experimentos 3 e 4, usando o circuito em série das Figura 7C, o qual é constituído por dois elementos R - EFC e a resistência da solução em série. Nessas condições, supõe-se que as constantes de tempo estão realcionadas a uma camada interna, composta por uma liga de cobre com baixo teor de estanho, e um fime externo, provavelmente, um produto de corrosão que, segundo a literatura [29,30], pode ser formado por $\mathrm{CuCl}$ ou $\mathrm{Cu}_{2} \mathrm{O}$ e $\mathrm{SnO}_{4}$. Desse modo, o valor de $\mathrm{R}_{\mathrm{tc}}$ deverá refletir a soma das resistências dessas camadas. Em todos os casos, o ajuste da simulação foi considerado bom para um valor de erro menor que $1 \%$ [32].

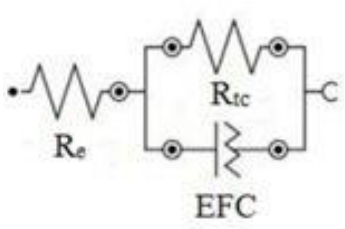

(A)

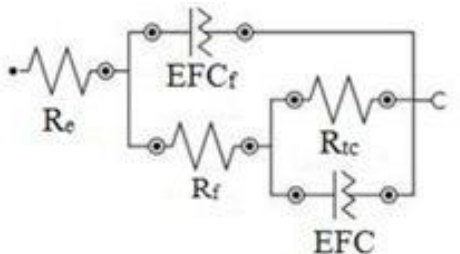

(B)

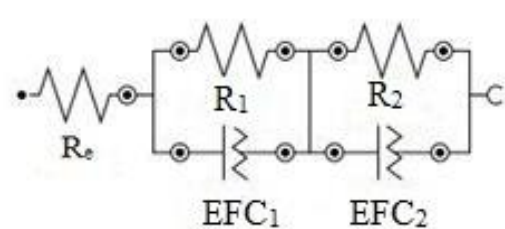

(C)

Figura 7: Modelos de circuitos equivalentes utilizados para simular os dados de EIE. (A) Modelo de circuito equivalente utilizado para simular os dados de EIE do aço carbono. (B) Modelo de circuito equivalente utilizado para simular os dados de EIE para os revestimentos Cu-Sn (Experimentos 1 e 2). (C) Modelo de circuito equivalente utilizado para simular os dados de EIE para os revestimentos $\mathrm{Cu}-\mathrm{Sn}$ (Experimentos 3 e 4).

Os valores de $\mathrm{R}_{\mathrm{tc}}$ e de $\mathrm{C}_{\mathrm{DCE}}$, obtidos após a simulação dos dados de EIE de todos os ensaios, estão apresentados na Tabela 4 . $\mathrm{O}$ valor da capacitância da dupla camada elétrica $\left(\mathrm{C}_{\mathrm{DCE}}\right)$ foi calculado a partir da admitância do elemento de fase constante (EFC), empregando a equação 2 [33,34].

$$
\mathrm{C}_{\mathrm{DCE}}=(\mathrm{EFC})^{\frac{1}{\mathrm{~N}}} \times R_{e f}^{\left(\frac{1}{\mathrm{~N}}-1\right)}
$$

onde o valor de $\mathrm{R}_{\mathrm{ef}}$ representa a resistência efetiva [34], que pode ser calculada pela equação 3: 


$$
R_{e f}=\frac{R_{e} R_{t c}}{R_{e}+R_{t c}}
$$

Essa tabela também apresenta os valores de $\mathrm{N}$, termo que define o grau de equivalência do elemento de fase constante para um componente capacitivo, bem como os valores de $\mathrm{R}_{\mathrm{f}}$ e da capacitância da dupla camada dos filmes obtidos para os ensaios de cada revestimento $\mathrm{Cu}-\mathrm{Sn}\left(\mathrm{C}_{\mathrm{DCEf}}\right)$, a qual foi calculada também usando as equações 1 e 2 .

Os valores observados confirmam o que foi visto nos diagramas de EIE da Figura 6. Para os revestimentos produzidos a partir da Solução 1 (contendo a maior concentração de $\mathrm{Sn}^{2+}$ ), foram verificados menores valores de $\mathrm{R}_{\mathrm{tc}}$ e maiores valores de $\mathrm{C}_{\mathrm{DCE}}$ em comparação ao substrato de aço nu, evidenciando que os filmes formados não se mostraram eficientes em mitigar o processo de corrosão do substrato. Os elevados valores de $\mathrm{C}_{\mathrm{DCE}}$ podem ser relacionados à produção de produtos de corrosão orindos do substrato, que apresentam características condutoras. Adicionalmente, a morfologia dendrítica apresentada pelo revestimento produzido nas condições do Experimento 2 (Figura 2D) e sua característica de baixa aderência [17], além da baixa espessura apresentada por esse filme, deve ter contribuído para esse ter o pior resultado entre todos os filmes estudados.

Os revestimentos de $\mathrm{Cu}-\mathrm{Sn}$ obtidos no eletrólito com maior concentração de íons $\mathrm{Cu}^{2+}$ (Solução 2) apresentaram maiores valores de $\mathrm{R}_{\mathrm{tc}}$, indicando que o filme formado na superfície do substrato de aço-carbono dificultou o processo de transferência de carga. Porém, enquanto um menor valor de capacitância foi verificado para o revestimento produzido nas condições do Experimento 3, nota-se que houve um aumento do valor de $\mathrm{C}_{\mathrm{DCE}}$ do filme preparado usando as condições do Experimento 4, em comparação com o ensaio para o aço carbono, o que pode estar relacionado com os resultados observados no diagrama de fase (Figura 6C), caracterizando a formação de um filme pouco protetor, nesse caso.

Tabela 4: Valores obtidos a partir da simulação dos dados de EIE para o aço carbono e revestimentos $\mathrm{Cu}-\mathrm{Sn}$ em meio de $\mathrm{NaCl}$ 0,5 mol.L-1.

\begin{tabular}{|c|c|c|c|c|c|c|c|c|}
\hline AMOSTRAS & $\begin{array}{l}R_{e} \\
(\Omega)\end{array}$ & $\begin{array}{c}\mathbf{R}_{\mathrm{f}} \\
\left(\Omega \mathrm{cm}^{2}\right)\end{array}$ & $\begin{array}{c}C_{\text {DCEf }} \\
\left(F_{\mathrm{cm}^{-2}}\right)\end{array}$ & $\begin{array}{c}R_{1} \\
\left(\Omega \mathrm{cm}^{2}\right)\end{array}$ & $\begin{array}{c}\mathbf{R}_{2} \\
\left(\Omega \mathrm{cm}^{2}\right)\end{array}$ & $\begin{array}{c}R_{\mathrm{tc}} \\
\left(\Omega \mathrm{cm}^{2}\right)\end{array}$ & $\begin{array}{c}\mathrm{C}_{\mathrm{DCE}} \\
\left(\mathrm{F} \mathrm{cm}^{-2}\right)\end{array}$ & $\mathbf{N}$ \\
\hline AÇO CARBONO & 6,31 & - & - & & - & 960,4 & $4,38 \times 10^{-4}$ & 0,746 \\
\hline $\begin{array}{l}\text { SOLUÇÃO 1e } \\
\text { j = } 10 \text { A.m.2 (1) }\end{array}$ & 6,79 & 21,41 & $7,80 \times 10^{-4}$ & & - & 798,7 & $1,71 \times 10^{-3}$ & 0,701 \\
\hline $\begin{array}{c}\text { SOLUÇÃO 1 e } \\
\text { j = } 100 \text { A.m }{ }^{-2}(2)\end{array}$ & 6,15 & 26,31 & $6,51 \times 10^{-5}$ & & - & 686,1 & $6,33 \times 10^{-4}$ & 0,581 \\
\hline $\begin{array}{l}\text { SOLUÇÃO 2 e } \\
\text { j = } 10 \text { A.m }{ }^{-2}(3)\end{array}$ & 6,12 & - & - & 11,07 & 1180,9 & 1191,9 & $5,90 \times 10^{-5}$ & 0,843 \\
\hline $\begin{array}{l}\text { SOLUÇÃO 2 e } \\
\text { j = } 100 \text { A.m }^{-2}(4)\end{array}$ & 6,12 & - & - & 42,97 & 1195,6 & 1238,6 & $1,79 \times 10^{-3}$ & 0,899 \\
\hline
\end{tabular}

De acordo com os resultados de ICP-OES apresentados na Tabela 3, verificou-se que teores de $\% \mathrm{~m} / \mathrm{m}$ Sn foram $\leq 3,44$ foram obtidos nas condições usadas para o presente estudo. Geralmente, revestimentos produzidos contendo maiores teores de $\mathrm{Sn}$ são relatados como apresentando características anticorrosivas. Silva et al. [12] mostraram que revestimentos de $\mathrm{Cu}-\mathrm{Sn}$ produzidos a partir de banho contendo tartarato de sódio apresentaram propriedade anticorrosiva em meio de $\mathrm{NaCl} 0,5 \mathrm{~mol} . \mathrm{L}^{-1}$ apenas quando a composição dos filmes foi próxima àquela do bronze comercial $(95 \% \mathrm{~m} / \mathrm{m} \mathrm{Cu}$ e $5 \% \mathrm{~m} / \mathrm{m} \mathrm{Sn})$. Surme et al.[4] também obtiveram revestimentos $\mathrm{Cu}$-Sn produzidos a partir de oxalato de sódio, com boas propriedades anticorrosivas em meio de $\mathrm{H}_{2} \mathrm{SO}_{4}$ 0,1 mol. $\mathrm{L}^{-1}$, quando teores de $\mathrm{Sn}$ no revestimento $\geq 25,4 \% \mathrm{~m} / \mathrm{m}$ foram obtidos. Desse modo, o banho contendo glicina como agente complexante, no valor de $\mathrm{pH}$ utilizado no presente trabalho, não foi eficiente para proporcionar revestimentos com teores de $\% \mathrm{~m} / \mathrm{m} \mathrm{Sn}$ satisfatórios para a obtenção de uma resistência à corrosão adequeda, já que os filmes formados não foram, aparentemente, capazes de evitar a continuidade do processo corrosivo dos substratos de aço no eletrólito.

Contudo, é importante lembrar que o revestimento produzido nas condições do Experimento 3 (Solução $\left.2, \mathrm{j}=10 \mathrm{~A} \cdot \mathrm{m}^{-2}\right)$ apresentou um elevado valor de $\mathrm{R}_{\mathrm{tc}}\left(\sim 1192 \Omega . \mathrm{cm}^{2}\right)$ e um baixo valor de $\mathrm{C}_{\mathrm{DCE}}\left(5,90 \times 10^{-5}\right.$ F. $\left.\mathrm{cm}^{-2}\right)$. Esse filme apresentou o maior valor de espessura calculada $(3,44 \mu \mathrm{m})$ e, possivelmente um produto de corrosão formado apenas por $\mathrm{Cu}_{2} \mathrm{O}$ e $\mathrm{SnO}_{4}$, fatores que podem ter contribuído para o resultado obtido. A menor espessura, o menor teor de $\mathrm{Sn}$ e a possível presença de $\mathrm{CuCl}$ na superfície do revestimento preparado nas condições do Experimento 4 (Solução 2, j = 100 A.m ${ }^{-2}$ ) podem, por sua vez, ter contribuído para uma 
camada não protetora na superfície do substrato. A presença de um filme de $\mathrm{CuCl}$ aumenta consideravelmente a condutividade da camada de eletrólito sobre o metal [35].

\subsubsection{Polarização Potenciodinâmica}

As curvas de polarização potenciodinâmica, catódicas e anódicas obtidas para os revestimentos $\mathrm{Cu}-\mathrm{Sn}$ e para o substrato de aço-carbono no eletrólito de $\mathrm{NaCl} 0,5$ mol. $\mathrm{L}^{-1}$ estão apresentadas na Figura 8. É possível observar que as curvas de polarização para todos os revestimentos de liga $\mathrm{Cu}-\mathrm{Sn}$ encontram-se deslocadas para potenciais mais negativos e maiores valores de densidade de corrente de corrosão, em comparação com as curvas obtidas para o substrato de aço nu. Esse resultado indica um aumento do processo corrosivo para os ensaios em que os revestimentos metálicos estavam presentes.

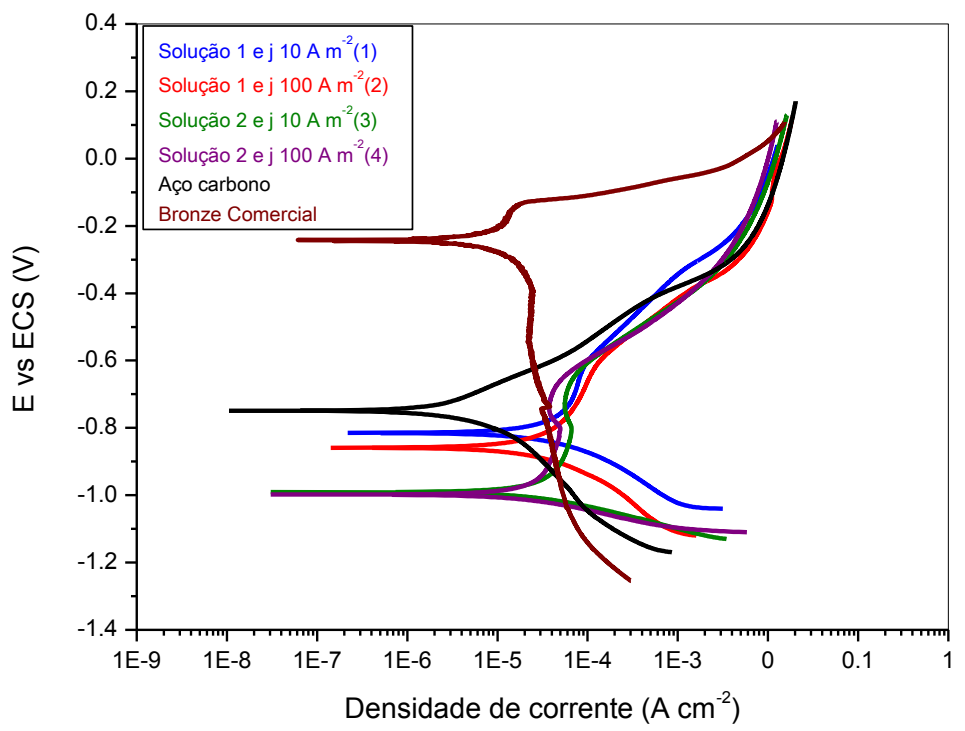

Figura 8: Curvas de polarização para os revestimentos $\mathrm{Cu}-\mathrm{Sn}$ e para o aço carbono em meio de $\mathrm{NaCl}$ 0,5 mol. $\mathrm{L}^{-1}$

Nota-se ainda, na Figura 8, que as curvas obtidas a partir dos revestimentos obtidos usando os Experimentos 3 e 4 apresentam uma região no ramo anódico onde se percebe mais nitidamente uma condição de passivação. Contudo, confirmando o que foi visto anteriormente na técnica de EIE, esses filmes não protegeram suficientemente o metal de base. Embora as curvas levantadas para os revestimenos produzidos a partir dos Experimentos 1 e 2 também tenham apresentado comportamento semelhante, a faixa de passivação observada para os filmes produzidos nessas condições foi menos significativa.

Para efeito de comparação, uma amostra de bronze comercial $(95.35 \% \mathrm{~m} / \mathrm{m} \mathrm{Cu}, 4.42 \% \mathrm{~m} / \mathrm{m} \mathrm{Sn}$, $0.053 \% \mathrm{~m} / \mathrm{m} \mathrm{Pb}, 0.080 \% \mathrm{~m} / \mathrm{m} \mathrm{Zn}, 0.058 \% \mathrm{~m} / \mathrm{m} \mathrm{Fe}$ e $0.006 \% \mathrm{~m} / \mathrm{m} \mathrm{P}$ ) foi ensaiada nas mesmas condições e seus resultados também são apresentados na Figura 8. Verifica-se que todas as curvas de polarização obtidas a partir dos revestimentos produzidos sobre o substrato de aço mostram valores de potenciais de corrosão mais negativos e também maiores valores de densidade de corrente de corrosão, do que para o bronze comercial $\left(E_{\text {corr }}=-0,242 \mathrm{~V} ; j_{\text {corr }}=1,33 \times 10^{-6} \mathrm{~A} \cdot \mathrm{m}^{-2}\right)$. Contudo, é importante ressaltar que os resultados obtidos para um revestimento e para um material maciço não podem ser comparados diretamente, em função de possíveis porosidades e defeitos geralmente existentes em um filme eletrodepositado. Além disso, o substrato é menos nobre que o revestimento e os ensaios de polarização refletem o resultado em conjunto do sistema revestimento/substrato [36].

Assim, os resultados de polarização potenciodinâmica confirmam o que foi visto nos ensaios de EIE, evidenciando que os revestimentos depositados no disco de aço não caracterizaram um filme protetor, não sendo capaz de evitar a aceleração do processo corrosivo no meio estudado.

\section{CONCLUSÕES}

Revestimentos metálicos foram produzidos em dois banhos eletrolíticos contendo diferentes concentrações de cobre e estanho visando a obtenção de ligas metálicas de $\mathrm{Cu}-\mathrm{Sn}$ através da técnica de eletrodeposição. A 
partir das análises de MEV foi possível verificar que revestimentos uniformes e com diferentes morfologias (associadas com o tipo de banho e densidade de corrente aplicada) foram obtidos. A técnica de EDS e as análises químicas confirmaram que os elementos ( $\mathrm{Cu}$ e $\mathrm{Sn}$ ) foram eletrodepositados, formando os revestimentos contendo os dois metais, em quantidades diferenciadas, dependendo das condições empregadas. Porém, ao caracterizar os revestimentos eletroquimicamente através das técnicas de EIE e polarização potenciodinâmica, foi observado que os filmes formados não eram protetores, não sendo capazes de evitar a aceleração do processo corrosivo.

A glicina utilizada neste trabalho como complexante em meio ácido pode ter formado preferencialmente complexos Sn-Glicina estáveis, o que favoreceu a deposição de íons $\mathrm{Cu}^{+2}$. Isto pode estar relacionado com o fato dos filmes formados não terem apresentado resistência à corrosão satisfatória, já que maiores resistências à corrosão em ligas $\mathrm{Cu}$-Sn estão associadas com o aumento do teor de Sn na liga.

A presença de $\mathrm{CuCl}_{2}{ }^{-}$, em função do meio usado conter $\mathrm{HCl}$, pode ter contribuído para a morfologia dos revestimentos de $\mathrm{Cu}-\mathrm{Sn}$, principalmente a partir da Solução 2. Esse fato comprova que a complexação dos íons $\mathrm{Cu}^{2+}$ pela glicina em meio ácido não ocorreu de maneira satisfatória.

Assim, pode-se concluir que o banho eletrolítico contendo glicina em $\mathrm{pH}$ ácido não foi eficiente para produzir filmes de $\mathrm{Cu}-\mathrm{Sn}$ resistentes à corrosão, sugerindo que a atuação deste complexante requer que um meio menos ácido seja utilizado.

\section{BIBLIOGRAFIA}

[1] SILVA, F., DO LAGO, D., D'ELIA, E., et al., "Electrodeposition of $\mathrm{Cu}-\mathrm{Zn}$ alloy coatings from citrate baths containing benzotriazole and cysteine as additives", Journal of applied electrochemistry, v.40, n. 11, pp. 2013-2022, 2010.

[2] LANDOLT, D. "Electrochemical and materials science aspects of alloy deposition", Electrochimica Acta, v.39, n. 8, pp. 1075-1090, 1994.

[3] WANG, Y., WAN, Y., ZHAO, S.M., et al., "Electrodeposition and characterization of $\mathrm{Al} 2 \mathrm{O} 3-\mathrm{Cu}(\mathrm{Sn})$, $\mathrm{CaF} 2-\mathrm{Cu}(\mathrm{Sn})$ and talc-Cu (Sn) electrocomposite coatings", Surface and Coatings Technology, v.106, n. 2, pp. 162-166, 1998.

[4] SÜRME, Y., GÜRTEN, A.A., BAYOL, E., et al., "Systematic corrosion investigation of various $\mathrm{Cu}-\mathrm{Sn}$ alloys electrodeposited on mild steel in acidic solution: dependence of alloy composition", Journal of alloys and compounds, v.485, n. 1, pp. 98-103, 2009.

[5] FERREIRA, F., SILVA, F., LUNA, A.S., et al., "Response surface modeling and optimization to study the influence of deposition parameters on the electrodeposition of $\mathrm{Cu}-\mathrm{Zn}$ alloys in citrate medium", Journal of Applied Electrochemistry, v.37, n. 4, pp. 473-481, 2007.

[6] GARCIA, J.R., DO LAGO, D.C.B., SENNA, L.F.D. "Electrodeposition of Cobalt Rich Zn-Co alloy Coatings from Citrate Bath", Materials Research, v.17, n. 4, pp. 947-957, 2014.

[7] LIMA, T.G., ROCHA, B.A.A., BRAGA, A.V.C., et al., "Response surface modeling and voltammetric evaluation of Co-rich $\mathrm{Cu}-\mathrm{Co}$ alloy coatings obtained from glycine baths", Surface and Coatings Technology, v.276, n. pp. 606-617, 2015.

[8] RASHWAN, S., MOHAMED, A., ABDEL-WAHAAB, S., et al., "Electrodeposition and characterization of thin layers of $\mathrm{Zn}-\mathrm{Co}$ alloys obtained from glycinate baths", Journal of applied electrochemistry, v.33, n. 11, pp. 1035-1042, 2003.

[9] SZCZYGIEŁ, B., LASZCZYŃSKA, A., TYLUS, W. "Influence of molybdenum on properties of Zn-Ni and Zn-Co alloy coatings", Surface and Coatings Technology, v.204, n. 9, pp. 1438-1444, 2010.

[10] SENNA, L.F., DÍAZ, S., SATHLER, L. "Electrodeposition of copper-zinc alloys in pyrophosphatebased electrolytes ", Journal of Applied Electrochemistry, v.33, n. 12, pp. 1155-1161, 2003.

[11] HEIDARI, G., KHOIE, S.M., ABRISHAMI, M.E., et al., "Electrodeposition of Cu-Sn alloys: theoretical and experimental approaches", Journal of Materials Science: Materials in Electronics, v.26, n. 3, pp. 1969-1976, 2015.

[12] SILVA, P.S., SENNA, L.F., LAGO, D.C.B. "Cu-Sn Coatings Produced Using Environmentally NonAggressive Electrolyte Containing Sodium Tartrate", Materials Research, v.20, n. pp. 667-675, 2017.

[13] SURVILA, A., MOCKUS, Z., KANAPECKAITĖ, S., et al., "Codeposition of copper and tin from acid sulphate solutions containing gluconic acid", Journal of Electroanalytical Chemistry, v.647, n. 2, pp. 123- 
127, 2010.

[14] CARLOS, I., BIDOIA, E., PALLONE, E., et al., "Effect of tartrate content on aging and deposition condition of copper-tin electrodeposits from a non-cyanide acid bath", Surface and Coatings Technology, v.157, n. 1, pp. 14-18, 2002.

[15] CARLOS, I., SOUZA, C., PALLONE, E., et al., "Effect of tartrate on the morphological characteristics of the copper-tin electrodeposits from a noncyanide acid bath", Journal of applied electrochemistry, v.30, $\mathrm{n}$. 8, pp. 987-994, 2000.

[16] PAULA, M.S. "Avaliação da corrosão microbiológica do aço carbono 1020 em água do mar sintética na presença de bactérias redutoras de sulfato", Dissertação de M.Sc., Universidade do Estado do Rio de Janeiro, Rio de Janeiro, 2010.

[17] SILVA JR., J.C.S. "Estudo de eletrodeposição de ligas Cu-Sn em meio de citrato de sódio", Dissertação de M.Sc., Universidade do Estado do Rio de Janeiro, Rio de Janeiro, 2013.

[18] SELVI, S.T., RAMAN, V., RAJENDRAN, N., "Corrosion inhibition of mild steel by benzotriazole derivatives in acidic medium”, Journal of applied electrochemistry, v.33, n. 12, pp. 1175-1182, 2003.

[19] SATPATI, A., RAVINDRAN, P. "Electrochemical study of the inhibition of corrosion of stainless steel by 1, 2, 3-benzotriazole in acidic media", Materials Chemistry and Physics, v.109, n. 2, pp. 352-359, 2008.

[20] RODRIGUES, P., V. AOKI, I., ANDRADE, A.D., et al., "Effect of benzotriazole on electrochemical and corrosion behaviour of type 304 stainless steel in 2M sulphuric acid solution", British Corrosion Journal, v.31, n. 4, pp. 305-308, 1996.

[21] BRENNER, A. Electrodeposition of Alloys. v.I, Academic Press, New York, 734p, 1963.

[22] SUBRAMANIAN, B., MOHAN, S., JAYAKRISHNAN, S., "Structural, microstructural and corrosion properties of brush plated copper-tin alloy coatings", Surface and Coatings Technology, v.201, n. 3, pp. 1145-1151, 2006.

[23] HAN, C., LIU, Q., IVEY, D.G. "Nucleation of Sn and Sn-Cu alloys on Pt during electrodeposition from Sn-citrate and $\mathrm{Sn}-\mathrm{Cu}-$-citrate solutions", Electrochimica Acta, v.54, n. 12, pp. 3419-3427, 2009.

[24] ZANELLA, C., XING, S., DEFLORIAN, F. "Effect of electrodeposition parameters on chemical and morphological characteristics of $\mathrm{Cu}-\mathrm{Sn}$ coatings from a methanesulfonic acid electrolyte", Surface and Coatings Technology, v.236, n. pp. 394-399, 2013.

[25] CORREIA, A.N., FAÇANHA, M.X., LIMA-NETO, P., "Cu-Sn coatings obtained from pyrophosphatebased electrolytes", Surface and Coatings Technology, v.201, n. 16, pp. 7216-7221, 2007.

[26] TANTAVICHET, N., PRITZKER, M., "Copper electrodeposition in sulphate solutions in the presence of benzotriazole", Journal of Applied Electrochemistry. v. 36, n. 1, pp. 49-61, 2006.

[27] KUBLANOVSKY, V., LITOVCHENKO, K. "Mass transfer and mechanism of electrochemical reduction of copper (II) from aminoacetate electrolytes", Journal of Electroanalytical Chemistry, v.495, n. 1, pp. $10-18,2000$.

[28] DJURDJEVIC, P.; DJOKIC, D. "Protein interactions with bivalent tin. 1. Hydrolysis and complexation of tin (II) ion with glycine", Journal of inorganic biochemistry, v.62, n. 1, pp. 17-29, 1996.

[29] AMMELOOT, F., FIAUD, C., SUTTER, E.M.M. "Characterization of the oxide layers on a $\mathrm{Cu}-13 \mathrm{Sn}$ alloy in a $\mathrm{NaCl}$ aqueous solution without and with $0.1 \mathrm{M}$ benzotriazole. Electrochemical and photoelectrochemical contributions ", Electrochimica Acta. v. 44, n. 15, pp. 2549-2558, 1999.

[30] ROBBIOLA, L., TRA, T.T.M., DUBOT, P., et al., "Characterisation of anodic layers on $\mathrm{Cu}-10 \mathrm{Sn}$ bronze (RDE) in aerated $\mathrm{NaCl}$ solution", Corrosion Science, v. 50, n. 8, pp. 2205-2215, 2008.

[31] ELIAZ, N., VENKATAKRISHNA, K., HEGDE, A.C., "Electroplating and characterization of Zn-Ni, Zn-Co and Zn-Ni-Co alloys", Surface and Coatings Technology, v. 205, n.7, pp. 1969-1978, 2010.

[32] BAYOUDHA, S., OTHMANE, A., PONSONNET, L., et al., "Electrical detection and characterization of bacterial adhesion using electrochemical impedance spectroscopy-based flow chamber", Colloids and Surfaces A: Physicochem. Eng. Aspects, v. 318, n. 1-3, pp. 291-300, 2008.

[33] ORAZEM, M.E., TRBOLLET, B. Electrochemical Impedande Spectroscopy, John Wiley and Sons, Inc. New Jersey, 2008.

[34] HIRSCHORN, B., ORAZEM, M.E., TRBOLLET, B., et al., "Determination of effective capacitance and film thickness from constant-phase-element parameters", Electrochimica Acta, v. 55, n. 21, pp. 6218$6227,2010$. 
[35] MORCILlO, M., CHICO, B., MARIACA, L., et al., "Salinity in marine atmospheric corrosion: its dependence on the wind regime existing in the site", Corrosion Science, v. 42, n. 1, pp. 91-104, 2000.

[36] CREUS, J., MAZILLE, H., IDRISSI, H. "Porosity evaluation of protective coatings onto steel, through electrochemical techniques", Surface and Coatings Technology, v. 130, n. 2-3, pp. 224-232, 2000.

\section{ORCID}

Priscila Santos da Silva Lilian Ferreira de Senna Dalva Cristina Baptista do Lago https://orcid.org/0000-0001-5911-1328

https://orcid.org/0000-0002-6316-6687

https://orcid.org/0000-0002-5707-5893 